\title{
Simultaneous determination of gross alpha/beta activities in water by liquid scintillation counting and its applications in the environmental monitoring
}

Xiaoyun Li ( $\sim$ lixiaoyun_10@126.com )

China Institute of Atomic Energy

Shaolin Wang

China Institute of Atomic Energy

Hailin Lou

China Institute of Atomic Energy

Jingshun Pan

China Institute of Atomic Energy

Qian Dong

China Institute of Atomic Energy

Yifan Zheng

China Institute of Atomic Energy

Ling Chen

China Institute of Atomic Energy

\section{Research Article}

Keywords:

Posted Date: December 14th, 2021

DOI: https://doi.org/10.21203/rs.3.rs-1142509/v1

License: (9) This work is licensed under a Creative Commons Attribution 4.0 International License.

Read Full License 


\section{Title page}

Names of the authors: Xiaoyun Li*, Shaolin Wang, Hailin Lou, Jingshun Pan, Qian Dong, Yifan Zheng, Ling Chen

Title: Simultaneous determination of gross alpha/beta activities in water by liquid scintillation counting and its applications in the environmental monitoring

Affiliation and address of the authors: China Institute of Atomic Energy, Beijing 102413, China

E-mail address of the corresponding author: lixiaoyun 10@,126.com 


\title{
Simultaneous determination of gross alpha/beta activities in water by liquid scintillation counting and its applications in the environmental monitoring
}

Xiaoyun Li, Shaolin Wang, Hailin Lou, Jingshun Pan, Qian Dong, Yifan Zheng, Ling Chen China Institute of Atomic Energy, Beijing 102413, China

\begin{abstract}
Based on the standards of ISO11704-2018 and ASTM D7283-17, a method for simultaneous determination of gross alpha and gross beta activity concentrations in water by liquid scintillation counting (LSC) was established, which can be applied to various types of water samples in routine monitoring, such as drinking water, groundwater, geothermal water, seawater, and radioactive wastewater. The sample's $\mathrm{pH}$ value and concentrated volume must be controlled to avoid quenching as much as possible. The validation tests show that the deviations of gross alpha and gross beta activities can satisfy quality control requirements in a wide range of activity ratios. For the actual samples, the measurement results of the LSC method are in good agreement with those of the thick source method. Moreover, the LSC method performs better in detection limit and a simpler pretreatment process than the thick source method.
\end{abstract}

\section{Introduction}

Radioactivity is widely present in various kinds of water bodies, such as seawaters, rivers, drinking waters, groundwaters, and wastewaters. The measurements of gross alpha and gross beta activity concentrations are among the most effective methods for preliminary screening and evaluating the total radioactivity contents in samples. In China, the national standard for drinking water quality stipulates that the guidance values of gross alpha and gross beta are $0.5 \mathrm{~Bq} \mathrm{~L}^{-1}$ and 1 $\mathrm{Bq} \mathrm{L}^{-1}$, respectively ${ }^{1}$, which is the same as that of the WHO guideline ${ }^{2}$. For wastewater, the maximum allowable discharge concentrations of gross alpha and gross beta are $1 \mathrm{~Bq} \mathrm{~L}^{-1}$ and 10 
$\mathrm{Bq} \mathrm{L}^{-1}$, respectively ${ }^{3}$. Once the radioactivity index exceeds the limit values, nuclide analysis and evaluation should be carried out targeted. So it is essential to establish a sensitive, rapid, and simple method to measure gross alpha and gross beta activities in the water for routine monitoring of many samples. The gross alpha and gross beta activities in water can be measured by gas-flow proportional counting (or $\mathrm{ZnS}(\mathrm{Ag}$ ) solid scintillation counting) and liquid scintillation counting $(\mathrm{LSC})^{4-7}$. Compared with the formers, the latter can obtain a lower detection limit in a shorter time because of its $4 \pi$ detection efficiency and simple operation ${ }^{8-10}$.

A pulse shape analysis (PSA) equipped with LSC is used to discriminate $\alpha / \beta$ events, in which alpha and beta counts are stored in separate storage addresses of the multichannel analyzer (MCA). The PSA value can be set from 1 to 256 , and the optimal one needs to be chosen by measuring a pure alpha emitter solution and a pure beta emitter solution. Lower PSA value being set will cause more $\beta$-pulses to fall into the $\alpha$-MCA, and a higher PSA value will cause more $\alpha$-pulses to fall into the $\beta$-MCA. This misclassification can be minimized by using the optimized PSA value. Quenching must be considered in liquid scintillation measurement. Different degrees of quenching will change the optimal PSA value and affect the detection efficiency and the separation effect of $\alpha / \beta$. Researchers have deeply studied the quenching of LSC measurement. The factors causing quenching include the acid type and intensity ${ }^{12-13}$, total dissolved solids (TDS $)^{10,14-15}$, and color of samples $^{16-18}$. It is generally required to add nitric acid when environmental water samples are collected. However, the increase in acidity will lead to the rise of quenching. An alternative method is to concentrate samples under the condition of controlling the $\mathrm{pH}$ value to achieve the same quenching level ${ }^{6,19-20}$. Different types of water samples have different contents of soluble solids. The amount of dissolved solids in the sample is generally controlled to be no more than $400 \mathrm{mg}$ to ensure the formation of a homogeneous solution after mixing with a cocktail ${ }^{7}$. When the sample has color, a color quenching correction is required ${ }^{16}$.

In China, the approved methods for measuring gross alpha and gross beta activities in the water are the thick source methods. The purpose of this paper is to establish a method for the determination of alpha and beta activities in water by LSC based on ISO11704-2018 and ASTM D $7283-17^{7}$ standards. And suitable pretreatment conditions are experimented. By controlling the sample acidity and concentration ratio, etc., the quenching level of the sample is controlled, so that the method can be used in routine monitoring for different types of water. For the actual water 
samples, the reliability and applicability of the LSC method are further investigated by comparing the results of the thick source method.

\section{Materials and methods}

\section{Apparatus}

An ultra-low background liquid scintillation spectrometer Wallac 1220 Quantulus manufactured by PerkinElmer (Finland, 2002) has been used for the measurements. A PSA is provided to discriminate $\alpha$ from $\beta$ radiations and an external standard source of ${ }^{152} \mathrm{Eu}$ to obtain external quench parameter $\mathrm{SQP}(\mathrm{E})$ for indicating the quench levels of samples.

A BH1227 4-channel low background $\alpha / \beta$ measuring assembly equipped with $\mathrm{ZnS}(\mathrm{Ag})$ solid scintillation counters (China Nuclear Control System Engineering Co. Ltd) was used to measure the conventional thick source method.

A Lei-ci PHS-3G pH-meter and a Lei-ci DDSJ-308F conductivity meter (Shanghai INESA Scientific Instrument Co. Ltd, China) were used for $\mathrm{pH}$ and TDS measurements, respectively.

A high pure germanium gamma spectrometry with a broad energy detector (BE6530, Canberra, USA) was used to measure gamma-ray emitting radionuclides in water. Its relative efficiency is $60 \%$, and the energy resolution is $1.8 \mathrm{keV}$ at $1332.5 \mathrm{keV}$ of ${ }^{60} \mathrm{Co}$. The energy response range is from $15-3000 \mathrm{keV}$.

\section{Establishment of a method for the simultaneous measurement of gross alpha/beta activities in water by LSC}

Reagents and Materials. The pure ${ }^{241} \mathrm{Am}$ and ${ }^{90} \mathrm{Sr} /{ }^{90} \mathrm{Y}$ standard solutions were used for LSC calibration. ${ }^{241} \mathrm{Am}$ in $0.5 \mathrm{~mol} \mathrm{~L}^{-1} \mathrm{HNO}_{3}$ (radio-purity $>99.9 \%$ ) was provided by China Institute of Atomic Energy. ${ }^{90} \mathrm{Sr} /{ }^{90} \mathrm{Y}$ in $3 \mathrm{~g} \mathrm{~L}^{-1} \mathrm{HNO}_{3}$ was purchased from Czech Metrology Institute. Both of them were diluted with $3 \mathrm{~g} \mathrm{~L}^{-1} \mathrm{HNO}_{3}$ carrier solution. Then their activities were certified by the national first-class ionizing radiation metrology station with the values of $20.5 \pm 0.2 \mathrm{~Bq} \mathrm{~g}^{-1}$ and $31.1 \pm 0.3 \mathrm{~Bq} \mathrm{~g}^{-1}$ (with coverage factor $k=2$ for $95 \%$ confidence), respectively. ${ }^{40} \mathrm{~K}$ standard solution was prepared using $\mathrm{KCl}$ (guaranteed reagent, purity $>99.8 \%$ ) supplied by Macklin Biochemical Co. Ltd. (Shanghai, China). And the activity concentration of ${ }^{40} \mathrm{~K}$ was determined by 
using the ratio between natural and radioactive potassium. Cocktail Ultima Gold AB (PerkinElmer) and $20 \mathrm{~mL}$ polyethylene vials (PerkinElmer) were used for the LSC measurement.

Five solid salts of $\mathrm{NaCl}, \mathrm{MgCl}_{2}, \mathrm{CaCl}_{2}, \mathrm{Na}_{2} \mathrm{SO}_{4}$, and $\mathrm{NaHCO}_{3}$ (analytical reagent) were obtained from Sinopharm Chemical Reagent Co. Ltd. (China). They were used to prepare saline water as a chemical quenching agent. Nitric acid (guaranteed reagent) was used to prepare carrier solution and acidify samples with received. All aqueous solutions were prepared with deionized water.

Calibration procedure of LSC. During LSC measurement, all samples and cocktail volumes were maintained at $5 \mathrm{~mL}$ and $15 \mathrm{~mL}$, respectively. Sample activities were controlled by adding the quantity of the standard solution. The volumes of the final samples were made to $5 \mathrm{~mL}$ by adding nitric acid carrier solution $\left(\sim 3 \mathrm{~g} \mathrm{~L}^{-1}, \mathrm{pH}=1.59 \pm 0.03\right)$. All vials were placed inside the counter for at least two hours for dark adaptation before counting. For PSA optimization, $1 \mathrm{~g}$ of pure ${ }^{241} \mathrm{Am}$ and ${ }^{90} \mathrm{Sr} /{ }^{90} \mathrm{Y}$ standard solutions were measured under different PSA settings for $10 \mathrm{~min}$. And three replicates of each solution were performed. The blank sample consisted of $5 \mathrm{~mL} \mathrm{HNO}_{3}$ carrier solution plus $15 \mathrm{~mL}$ of Ultima Gold $\mathrm{AB}$ was measured under the same conditions for 1000 $\min$.

The most abundant ions in saline or seawater are $\mathrm{Na}^{+}, \mathrm{Mg}^{2+}, \mathrm{Ca}^{2+}, \mathrm{Cl}^{-}, \mathrm{SO}_{4}{ }^{2-}$ and $\mathrm{HCO}_{3}{ }^{-21-22}$. A simulated saline (SS) solution was prepared with five salts of $\mathrm{NaCl}, \mathrm{MgCl}_{2}, \mathrm{CaCl}_{2}, \mathrm{Na}_{2} \mathrm{SO}_{4}$, and $\mathrm{NaHCO}_{3}$, referring to the ratio of the ions in seawater and saline published in the literature. The $\mathrm{pH}$ value of the SS solution was adjusted to about 1.6 with $\mathrm{HNO}_{3}$, and the specific contents of these salts are shown in Table 1. Using SS solution as a chemical quenching agent, $0.5 \mathrm{~mL}, 1 \mathrm{~mL}$, $1.5 \mathrm{~mL}, 2 \mathrm{~mL}$, and $3 \mathrm{~mL}$ was added to the ${ }^{241} \mathrm{Am}$ and ${ }^{90} \mathrm{Sr} /{ }^{90} \mathrm{Y}$ standard solutions and measured under different PSA settings to investigate the quenching effect of TDS in the sample.

A series of spiked samples with ${ }^{241} \mathrm{Am},{ }^{90} \mathrm{Sr} /{ }^{90} \mathrm{Y}$, and ${ }^{40} \mathrm{~K}$ were used as test samples to validate the calibration curve. They were measured under an optimal PSA condition for $300 \mathrm{~min}$.

Sample pretreatment for LSC measurement. Based on the sample procedures recommended in the standard of ISO 11704: $2018^{6}$, different pretreatment methods were adopted according to the types and characteristics of samples. For environmental water, such as drinking water, surface 
water, groundwater, and geothermal water, a thermal pre-concentration method was used. Different concentration ratios were adopted depending on the salt content of the sample. Generally, prior to pretreatment, the TDS value of the sample was measured to judge the appropriate concentration ratio of the sample preliminarily. Then a weighed aliquot of the water sample of approximately $200-500 \mathrm{~g}$ was taken into a beaker, acidified with a certain amount of $\mathrm{HNO}_{3}$, and slowly evaporated to a final quantity of roughly $10-20 \mathrm{~g}$. The $\mathrm{pH}$ value of the concentrated aliquot was controlled at about 1.6. After cooled to room temperature, $5 \mathrm{~mL}$ of the concentrated aliquot was transferred into the vial and mixed with $15 \mathrm{~mL}$ of cocktail to obtain a homogeneous solution for LSC measurement. The measurement time was $300 \mathrm{~min}$. The remaining solution in the beaker was dried completely, and the residue was weighed to calculate the exact mass of solid $\left(m_{r}, \mathrm{mg}\right)$ in the sample of LSC measurement.

Samples with relatively high salt content such as seawater were directly measured after heating to remove the dissolved ${ }^{222} \mathrm{Rn}$. A weighed aliquot of the water sample of approximately $100 \mathrm{~g}$ was taken into a beaker, acidified with a certain amount of $\mathrm{HNO}_{3}$, and heated with a cover to around $80{ }^{\circ} \mathrm{C}$ while stirring for $30 \mathrm{~min}$. The $\mathrm{pH}$ value of the aliquot was controlled at about 1.6. After cooled to room temperature, $5 \mathrm{~mL}$ of the aliquot was transferred into the vial and mixed with 15 $\mathrm{mL}$ of the cocktail. Then the remaining solution in the beaker was dried completely and weighed to obtain the solid residue quality of the sample. The exact mass, $m$, of the sample analyzed was calculated using equation (1).

$$
m=\frac{m_{1} m_{3}}{m_{2}}
$$

Where $m_{1}$ is the mass of the initial sample subject to heating or concentration, $m_{2}$ is the mass of the heated or concentrated sample, and $m_{3}$ is the mass of heated or concentrated sample transferred in the vial. The radiation recoveries of the heating procedures, $\eta$, were determined by measurement of spiked ${ }^{241} \mathrm{Am}$ and ${ }^{90} \mathrm{Sr} /{ }^{90} \mathrm{Y}$ samples.

A direct counting method was generally adopted for the measurement of radioactive wastewater. After $\mathrm{pH}$ adjustment, we transferred $5 \mathrm{~mL}$ of the aliquot into the vial, closed it, and shook it vigorously to remove most of the dissolved ${ }^{222} \mathrm{Rn}$. Then the sample was mixed with $15 \mathrm{~mL}$ of cocktail for measurement. In addition, $50-100 \mathrm{~mL}$ of water sample was completely dried and weighed to obtain the solid residue quality of the sample. 
Calculations. Alpha/beta activity concentrations, standard uncertainties, and detection limits are calculated according to the equations shown in ASTM D7283-17 ${ }^{7}$ as follows.

$$
\varepsilon_{\alpha \alpha}=\frac{R_{\alpha \alpha}-R_{\alpha b}}{C_{\alpha} V_{s \alpha}}, \quad \varepsilon_{\alpha \beta}=\frac{R_{\alpha \beta}-R_{\beta b}}{C_{\alpha} V_{s \alpha}}, \quad \varepsilon_{\beta \beta}=\frac{R_{\beta \beta}-R_{\beta b}}{C_{\beta} V_{s \beta}}, \quad \varepsilon_{\beta \alpha}=\frac{R_{\beta \alpha}-R_{\alpha b}}{C_{\beta} V_{s \beta}}
$$

Where $\varepsilon_{\alpha \alpha}$ is detection efficiency of the ${ }^{241} \mathrm{Am}$ standard aliquot in the regions of interest (ROI) for alpha, $\varepsilon_{\alpha \beta}$ is detection efficiency of the ${ }^{241} \mathrm{Am}$ standard aliquot in the beta ROI, $\varepsilon_{\beta \beta}$ is detection efficiency of the ${ }^{90} \mathrm{Sr} /{ }^{90} \mathrm{Y}$ standard aliquot in the beta ROI, $\varepsilon_{\beta \alpha}$ is detection efficiency of the ${ }^{90} \mathrm{Sr} /{ }^{90} \mathrm{Y}$ standard aliquot in the alpha ROI. $R_{\alpha \alpha}$ is count rate of the ${ }^{241} \mathrm{Am}$ standard aliquot in the alpha ROI $\left(\mathrm{s}^{-1}\right), R_{\alpha \beta}$ is count rate of the ${ }^{241} \mathrm{Am}$ standard aliquot in the beta ROI $\left(\mathrm{s}^{-1}\right), R_{\beta \beta}$ is count rate of the ${ }^{90} \mathrm{Sr} /{ }^{90} \mathrm{Y}$ standard aliquot in the beta ROI $\left(\mathrm{s}^{-1}\right), R_{\beta \alpha}$ is count rate of the ${ }^{90} \mathrm{Sr} /{ }^{90} \mathrm{Y}$ standard aliquot in the alpha ROI $\left(\mathrm{s}^{-1}\right), R_{\alpha b}$ is count rate of the background sample in the alpha ROI $\left(\mathrm{s}^{-1}\right), R_{\beta b}$ is count rate of the background sample in the beta ROI $\left(\mathrm{s}^{-1}\right) . C_{\alpha}$ is activity concentration of the ${ }^{241} \mathrm{Am}$ standard solution $\left(\mathrm{Bq} \mathrm{g}{ }^{-1}\right), C_{\beta}$ is activity concentration of the ${ }^{90} \mathrm{Sr} /{ }^{90} \mathrm{Y}$ standard solution $(\mathrm{Bq}$ $\left.\mathrm{g}^{-1}\right), V_{s \alpha}$ is the volume of the ${ }^{241} \mathrm{Am}$ standard solution added to the vial $(\mathrm{g}), V_{s \beta}$ is the volume of the ${ }^{90} \mathrm{Sr} /{ }^{90} \mathrm{Y}$ standard solution added to the vial $(\mathrm{g})$.

$$
X_{\alpha}=\frac{\varepsilon_{\alpha \beta}}{\varepsilon_{\alpha \alpha}}, \quad X_{\beta}=\frac{\varepsilon_{\beta \alpha}}{\varepsilon_{\beta \beta}}
$$

Where $X_{\alpha}$ is alpha-to-beta spillover factor and $X_{\beta}$ is beta-to-alpha spillover factor.

The net count rates in the alpha ROI and beta ROI are calculated as follows.

$$
\begin{array}{ll}
R_{\alpha}=R_{\alpha \alpha}-R_{\alpha b}, & R_{\beta}=R_{\beta \beta}-R_{\beta b} \\
R_{\alpha}^{\prime}=\frac{R_{\alpha}-R_{\beta} X_{\beta}}{1-X_{\alpha} X_{\beta}}, & R_{\beta}^{\prime}=\frac{R_{\beta}-R_{\alpha} X_{\alpha}}{1-X_{\alpha} X_{\beta}}
\end{array}
$$

Where $R_{\alpha}$ is net count rate of the sample aliquot in the alpha ROI $\left(\mathrm{s}^{-1}\right)$ and $R_{\beta}$ is net count rate of the sample aliquot in the beta ROI $\left(\mathrm{s}^{-1}\right) . R_{\alpha}^{\prime}$ is alpha count rate corrected for spillover and $R_{\beta}^{\prime}$ is beta count rate corrected for spillover.

The sample gross alpha/beta activity concentrations are calculated from the following:

$$
A C_{\alpha}=\frac{R_{\alpha}^{\prime}}{\varepsilon_{\alpha \alpha} V}, \quad A C_{\beta}=\frac{R_{\beta}^{\prime}}{\varepsilon_{\beta \beta} V}
$$

Where $A C_{\alpha}$ is sample gross alpha activity concentration $\left(\mathrm{Bq} \mathrm{L}^{-1}\right)$ and $A C_{\beta}$ is sample gross beta activity concentration $\left(\mathrm{Bq} \mathrm{L}^{-1}\right) . V$ is sample aliquot volume (L).

The standard uncertainties of these parameters and alpha/beta activity concentrations are 
calculated using equations as specified in ISO/IEC Guide $98-3: 2008^{23}$ as follows.

$$
\begin{gathered}
u\left(R_{\alpha}\right)=\sqrt{\frac{R_{\alpha \alpha}}{t_{s}}+\frac{R_{\alpha b}}{t_{b}}}, \quad u\left(R_{\alpha \beta}-R_{\beta b}\right)=\sqrt{\frac{R_{\alpha \beta}}{t_{s}}+\frac{R_{\beta b}}{t_{b}}} \\
u\left(R_{\beta}\right)=\sqrt{\frac{R_{\beta \beta}}{t_{s}}+\frac{R_{\beta b}}{t_{b}}}, \quad u\left(R_{\beta \alpha}-R_{\alpha b}\right)=\sqrt{\frac{R_{\beta \alpha} t_{s}}{t_{s}}+\frac{R_{\alpha b}}{t_{b}}} \\
u\left(\varepsilon_{\alpha \alpha}\right)=\varepsilon_{\alpha \alpha} \cdot \sqrt{\frac{u^{2}\left(R_{\alpha}\right)}{\left(R_{\alpha \alpha}-R_{\alpha b}\right)^{2}}+\frac{u^{2}\left(C_{\alpha}\right)}{C_{\alpha}^{2}}+\frac{u^{2}\left(V_{s \alpha}\right)}{V_{s \alpha}^{2}}}, \quad u\left(\varepsilon_{\alpha \beta}\right)=\varepsilon_{\alpha \beta} \cdot \sqrt{\frac{u^{2}\left(R_{\alpha \beta}-R_{\beta b}\right)}{\left(R_{\alpha \beta}-R_{\beta b}\right)^{2}}+\frac{u^{2}\left(C_{\alpha}\right)}{C_{\alpha}^{2}}+\frac{u^{2}\left(V_{s \alpha}\right)}{V_{s \alpha}^{2}}}, \\
u\left(\varepsilon_{\beta \beta}\right)=\varepsilon_{\beta \beta} \cdot \sqrt{\frac{u^{2}\left(R_{\beta}\right)}{\left(R_{\beta \beta}-R_{\beta b}\right)^{2}}+\frac{u^{2}\left(C_{\beta}\right)}{C_{\beta}^{2}}+\frac{u^{2}\left(V_{s \beta}\right)}{V_{s \beta}^{2}}}, u\left(\varepsilon_{\beta \alpha}\right)=\varepsilon_{\beta \alpha} \cdot \sqrt{\frac{u^{2}\left(R_{\beta \alpha}-R_{\alpha b}\right)}{\left(R_{\beta \alpha}-R_{\alpha b}\right)^{2}}+\frac{u^{2}\left(C_{\beta}\right)}{C_{\beta}^{2}}+\frac{u^{2}\left(V_{s \beta}\right)}{V_{s \beta}^{2}}} \\
u\left(X_{\alpha}\right)=X_{\alpha} \cdot \sqrt{\frac{u^{2}\left(\varepsilon_{\alpha \beta}\right)}{\varepsilon_{\alpha \beta}^{2}}+\frac{u^{2}\left(\varepsilon_{\alpha \alpha}\right)}{\varepsilon_{\alpha \alpha}^{2}}}, \quad u\left(X_{\beta}\right)=X_{\beta} \cdot \sqrt{\frac{u^{2}\left(\varepsilon_{\beta \alpha}\right)}{\varepsilon_{\beta \alpha}^{2}}+\frac{u^{2}\left(\varepsilon_{\beta \beta}\right)}{\varepsilon_{\beta \beta}^{2}}} \\
u_{c}\left(R_{\alpha}^{\prime}\right)=\sqrt{\frac{u^{2}\left(R_{\alpha}\right)+X_{\beta}^{2} u^{2}\left(R_{\beta}\right)+R_{\alpha}^{\prime 2} X_{\beta}^{2} u^{2}\left(X_{\alpha}\right)+R_{\beta}^{\prime 2} u^{2}\left(X_{\beta}\right)}{1-X_{\alpha} X_{\beta}}} \\
u_{c}\left(R_{\beta}^{\prime}\right)=\sqrt{\frac{u^{2}\left(R_{\beta}\right)+X_{\alpha}^{2} u^{2}\left(R_{\alpha}\right)+R_{\beta}^{\prime 2} X_{\alpha}^{2} u^{2}\left(X_{\beta}\right)+R_{\alpha}^{\prime 2} u^{2}\left(X_{\alpha}\right)}{1-X_{\alpha} X_{\beta}}} \\
u_{c}\left(A C_{\alpha}\right)=\sqrt{\frac{u_{c}^{2}\left(R_{\alpha}^{\prime}\right)}{\varepsilon_{\alpha \alpha}^{2} V^{2}}+A C_{\alpha}^{2} \cdot\left(\frac{u^{2}(V)}{V^{2}}+\frac{1+X_{\alpha} X_{\beta}}{1-X_{\alpha} X_{\beta}} \cdot \frac{u^{2}\left(\varepsilon_{\alpha \alpha}\right)}{\varepsilon_{\alpha \alpha}^{2}}\right)} \\
\left.u_{c}\left(A C_{\beta}\right)=\sqrt{\frac{u_{c}^{2}\left(R_{\beta}^{\prime}\right)}{\varepsilon_{\beta \beta}^{2} \cdot V^{2}}+A C_{\beta}^{2} \cdot\left(\frac{u^{2}(V)}{V^{2}}+\frac{1+X_{\alpha} X_{\beta}}{1-X_{\alpha} X_{\beta}} \cdot \frac{u^{2}\left(\varepsilon_{\beta \beta}\right)}{\varepsilon_{\beta \beta}^{2}}\right.}\right)
\end{gathered}
$$

Where $u\left(R_{a}\right)$ is standard uncertainty of the net count rate of the sample aliquot in the alpha ROI, $u\left(R_{\beta}\right)$ is standard uncertainty of the net count rate of the sample aliquot in the beta ROI, $u\left(R_{\alpha \beta}-R_{\beta b}\right)$ is standard uncertainty of the net count rate of the ${ }^{241} \mathrm{Am}$ standard aliquot in the beta ROI, and $u\left(R_{\beta \alpha}-R_{\alpha b}\right)$ is standard uncertainty of the net count rate of the ${ }^{90} \mathrm{Sr} /{ }^{90} \mathrm{Y}$ standard aliquot in the alpha ROI. $u\left(\varepsilon_{\alpha \alpha}\right)$ is standard uncertainty of the alpha particle detection efficiency in the alpha ROI, $u\left(\varepsilon_{\alpha \beta}\right)$ is standard uncertainty of the alpha particle detection efficiency in the beta ROI, $u\left(\varepsilon_{\beta \beta}\right)$ is standard uncertainty of the beta particle detection efficiency in the beta ROI, and $u\left(\varepsilon_{\beta a}\right)$ is standard uncertainty of the beta particle detection efficiency in the alpha ROI. $u\left(X_{\alpha}\right)$ is standard uncertainty of the alpha spillover factor, and $u\left(X_{\beta}\right)$ is standard uncertainty of the beta spillover factor. $u_{c}\left(R_{\alpha}^{\prime}\right)$ is the combined standard uncertainty of the alpha count rate corrected for spillover, and $u_{c}\left(R_{\beta}^{\prime}\right)$ is the combined standard uncertainty of the beta count rate corrected for spillover. $u_{c}\left(A C_{a}\right)$ is the combined standard uncertainty of the sample gross alpha activity concentration, and $u_{c}\left(A C_{\beta}\right)$ is the combined standard uncertainty of the sample gross beta activity concentration. 
Minimum detectable concentrations (MDC) for gross alpha and gross beta activity concentrations are calculated using equations as follows.

$$
\begin{aligned}
& \mathrm{MDC}_{\alpha}= \frac{\left.2.71 \cdot \frac{\left(1+\mathrm{X}_{\alpha} \mathrm{X}_{\beta}^{2}\right)}{\mathrm{t}_{\mathrm{s}} \cdot\left(1-\mathrm{X}_{\alpha} \mathrm{X}_{\beta}\right)}+3.29 \cdot \sqrt{\frac{\mathrm{AC_{ \beta }} \cdot \mathrm{V} \cdot \varepsilon_{\beta \alpha} \cdot\left(1+\mathrm{X}_{\beta}\right)}{\mathrm{t}_{\mathrm{s}}}+\left(\mathrm{R}_{\alpha \mathrm{b}}+\mathrm{X}_{\beta}^{2} \mathrm{R}_{\beta \mathrm{b}}\right) \cdot\left(\frac{1}{\mathrm{t}_{\mathrm{s}}}+\frac{1}{\mathrm{t}_{\mathrm{b}}}\right.}\right)}{\varepsilon_{\alpha \alpha} \cdot \mathrm{V} \cdot\left(1-\mathrm{X}_{\alpha} \mathrm{X}_{\beta}\right)} \\
& \mathrm{MDC}_{\beta}=\frac{\left.2.71 \cdot \frac{\left(1+\mathrm{X}_{\beta} \mathrm{X}_{\alpha}^{2}\right)}{\mathrm{t}_{\mathrm{s}} \cdot\left(1-\mathrm{X}_{\alpha} \mathrm{X}_{\beta}\right)}+3.29 \cdot \sqrt{\frac{A \mathrm{C}_{\alpha} \cdot \mathrm{V} \cdot \varepsilon_{\alpha \beta} \cdot\left(1+\mathrm{X}_{\alpha}\right)}{\mathrm{t}_{\mathrm{s}}}+\left(\mathrm{R}_{\beta \mathrm{b}}+\mathrm{X}_{\alpha}^{2} \mathrm{R}_{\alpha \mathrm{b}}\right) \cdot\left(\frac{1}{\mathrm{t}_{\mathrm{s}}}+\frac{1}{\mathrm{t}_{\mathrm{b}}}\right.}\right)}{\varepsilon_{\beta \beta} \cdot \mathrm{V} \cdot\left(1-\mathrm{X}_{\alpha} \mathrm{X}_{\beta}\right)}
\end{aligned}
$$

Where $t_{s}$ is sample aliquant count time in seconds, and $t_{b}$ is background aliquant count time in seconds.

\section{Determination of the $\gamma$-radionuclides by gamma spectrometry}

For samples with gross alpha or gross beta activity concentrations exceeding the management limits, gamma spectrometry was first used to determine radionuclides such as $\mathrm{U}, \mathrm{Th}, \mathrm{Ra},{ }^{137} \mathrm{Cs}$, ${ }^{40} \mathrm{~K}$, etc. Samples of about $240 \mathrm{~g}$ were transferred in a cylindrical plastic container $7.5 \mathrm{~cm}$ in diameter and $7 \mathrm{~cm}$ in height for counting of $1440 \mathrm{~min}$. If necessary, more specific analytical strategies would be developed.

\section{Results and discussion}

\section{Establishment of LSC method}

Optimization of counting conditions. According to LSC spectrums and the figure of merit $\left(E^{2}\right.$ $\mathrm{B}^{-1}$ ), the ROIs for alpha and beta counting were from 400-800 channel and 250-950 channel, respectively. All alpha events with the energy of $4-8 \mathrm{MeV}$ and all beta events except tritium can be detected in the ranges. The alpha and beta spillover factors for each PSA setting were calculated, and the variation curves along with the PSA were shown in Fig. 1. From Fig. 1, the optimal PSA value is 108 , and the minimum interference value is $1.51 \%$. Other optimal parameters, including efficiencies of ${ }^{241} \mathrm{Am}$ and ${ }^{90} \mathrm{Sr} /{ }^{90} \mathrm{Y}$ standard aliquot and background sample count rates, were all shown in Table 2.

Calibration of the saline water sample. Solid salts dissolved in water samples cause a certain degree of quenching, which will affect the detection efficiencies and spillover factors of alpha and 
beta. Therefore, we investigated the effect of different salt content on alpha-beta separation. $1 \mathrm{~g}$

${ }^{241} \mathrm{Am}$ or ${ }^{90} \mathrm{Sr} /{ }^{90} \mathrm{Y}$ standard solution was mixed with varying volumes of SS solution and measured under different PSA settings. The results show that the SQP(E) value change was not sensitive to increasing salt content. When salt content increased from $60 \mathrm{mg}$ to $360 \mathrm{mg}$, SQP(E) value decreased slowly from $797.7 \pm 4.9$ to $791.4 \pm 5.2$, and the optimal PSA values of these samples fluctuated in a narrow range from 106 to 109 , but the sum of $X_{\alpha}$ and $X_{\beta}$ increased. The graphs of $\varepsilon_{a a}, \varepsilon_{\alpha \beta}, \varepsilon_{\beta \beta}, \varepsilon_{\beta \alpha}, X_{\alpha}$, and $X_{\beta}$ concerning salt mass are shown in Fig.2. With the increase of solid mass, the detective efficiencies of ${ }^{241} \mathrm{Am}$ and ${ }^{90} \mathrm{Sr} /{ }^{90} \mathrm{Y}$ decreased from $100.5 \%$ and $94.9 \%$ to $97.3 \%$ and $90.6 \%$, respectively, while the misclassification efficiencies and spillover factors of $\alpha / \beta$ both increased. The fitting curves of these six parameters with the change of solid mass are listed in Table 3.

\section{Validation for LSC method}

The spiked samples. The ${ }^{241} \mathrm{Am},{ }^{90} \mathrm{Sr}-{ }^{90} \mathrm{Y}$, and ${ }^{40} \mathrm{~K}$ standard solutions were mixed with nitric acid carrier or SS solution to prepare three series of spiked samples with different activity levels for method validation. The samples are numbered according to the activity levels. If it is greater than $5 \mathrm{~Bq}$, indicated by $\mathrm{H}$, being between $0.5 \mathrm{~Bq}$ to $5 \mathrm{~Bq}$ will be indicated by $\mathrm{M}$, and being less than $0.5 \mathrm{~Bq}$, indicated by $\mathrm{L}$. The measurement results are shown in Table 4-6, and the comparison graphs of the activity relative deviations of alpha and beta for three series of spiked samples are shown in Figure S.1. The pure spiked sample was prepared by ${ }^{241} \mathrm{Am},{ }^{90} \mathrm{Sr}-{ }^{90} \mathrm{Y}$, or ${ }^{40} \mathrm{~K}$ standard solution with nitric acid carrier solution, and the mixed spiked samples were prepared by mixing ${ }^{241} \mathrm{Am}$ and ${ }^{90} \mathrm{Sr}^{-90} \mathrm{Y}$ standard solutions. For the pure spiked samples (Table 4), the activity deviations were within $7 \%$. For the mixed spiked samples, the activity ratio of gross alpha and gross beta ranged from 1:102 to 67:1. And the relative deviations of gross alpha and gross beta were less than $8 \%$ and less than $17 \%$, respectively. For the case of non-quenching samples (Table 5), when the activity ratio of gross alpha and gross beta was about 1 , such as $L_{\alpha} L_{\beta}, M_{\alpha} M_{\beta}$, and $\mathrm{H}_{\alpha} \mathrm{H}_{\beta}$ samples, the deviations of gross alpha and gross beta fluctuated little. When the activity ratio of gross alpha and gross beta increased from 1:6 to 1:85, such as $M_{\alpha} H_{\beta}, L_{\alpha} M_{\beta}$, and $L_{\alpha} H_{\beta}$ samples, the alpha deviations was increased from $0.6 \%$ to $7.6 \%$ due to the effect of high beta activity. For the samples with high alpha and low beta activities, the gross beta activity was less affected by 
gross alpha activity, and the deviation was less than 5\%. Bhade SPD and Zapata Garcia D have also reported similar phenomena ${ }^{11-12}$.

When soluble salts exist in solutions (Table 6), for medium and high activity samples, such as $\mathrm{M}_{\alpha} \mathrm{M}_{\beta}$ and $\mathrm{H}_{\alpha} \mathrm{H}_{\beta}$, the activity deviations of gross alpha and gross beta changed little. But for low activity samples, such as $\mathrm{L}_{\alpha} \mathrm{L}_{\beta}$, the gross alpha and gross beta activities also showed negative deviations. The gross alpha activities for the samples of $L_{\alpha} M_{\beta}$ and $L_{\alpha} H_{\beta}$ and the gross beta activities for the samples of $M_{\alpha} L_{\beta}$ and $H_{\alpha} L_{\beta}$ showed negative variation in varying degrees, which indicated that the calibration curve had some variation for these samples. It is known that the optimal PSA value is affected by many factors, one of which is the activity concentration of standard nuclide. When the activity or activity ratio of standard solutions used for calibration is greatly different from the state of the measured sample, the optimal PSA value will occur to displacement ${ }^{11,16}$. It also makes the values of calibration parameters such as $X_{\alpha}$ and $X_{\beta}$ deviate. The larger the quenching of the sample accompanied with the more significant the displacement of PSA value, which will cause the more considerable the deviation of the calculated results occurred. We tried to avoid quenching in the analysis of samples, and monitor the quenching level by SQP(E) value so that the activity deviations of samples can be controlled within $30 \%$, which satisfies the quality control requirements for routine monitoring.

The intercomparison samples. Our laboratory participated in proficiency tests for the gross alpha/beta of water samples organized by the National Institute for Radiological Protection, China CDC, in 2019 and 2020. The total numbers of institutions participating in the proficiency test were 121 and 127, respectively. The results were evaluated by the Z-Score method, and the reference value was measured by the designated organizations.

The samples we received were colorless, so the color quenching was not considered in LSC measurement. And chemical quenching correction was mainly based on the salt content in the water sample. Under the condition of controlling the $\mathrm{pH}$ value of the solution, about $200 \mathrm{ml}$ aqueous solution was concentrated to about $10 \mathrm{ml}$, and then $5 \mathrm{ml}$ solution was transferred into the vial. Through spiked experiments, the average radiochemical recovery of the LSC method was 99.1\%. The calculation results of activity concentrations of samples are shown in Table 7. From the SQP (E) values, acidity and solid content slightly affect the quenching. The absolute values of 
Z-Scores are all less than 2.0, in agreement with the reference values, which indicate the LSC method can provide satisfactory results.

\section{Realistic applications}

According to the currently reported literature, the countries that use the LSC method for routine monitoring mainly are Spain, Italy, Serbia, Finland, Mexico, and the United States. The types of water samples monitored include drinking water (well water, bottled purified water, and bottled mineral water), surface water, and groundwater ${ }^{8-10,15,17,24-26}$. However, the LSC method has not been approved in China, which is limited for laboratory research, and has not been applied for routine monitoring.

In this part, five representative types of water samples were selected, which were drinking water (DW), groundwater (GW), geothermal water (GT), seawater (SW), and wastewater (WW). By comparing the LSC method and the thick source method, the applicability of the LSC method for real sample monitoring was further investigated. The measurement results are shown in Table 8 . Overall, the relative deviations of gross alpha and gross beta for ten samples were less than $15 \%$, indicating that the two measurement methods were well comparable for these real water samples. For the cases of drinking water, groundwater, and geothermal water, the activity concentrations of gross $\alpha$ and gross $\beta$ are less than $0.5 \mathrm{~Bq} / \mathrm{L}$ and $1 \mathrm{~Bq} / \mathrm{L}$, respectively. For the case of seawater samples, the activity concentrations of gross $\alpha$ are less than $0.5 \mathrm{~Bq} / \mathrm{L}$, and the activity concentrations of gross $\beta$ are $9-10 \mathrm{~Bq} / \mathrm{L}$. The main nuclide is ${ }^{40} \mathrm{~K}$ determined by gamma spectrometry. For the two wastewater samples, the activity concentrations of gross $\alpha$ and $\beta$ are higher than the environmental levels, mainly containing ${ }^{241} \mathrm{Am}$ and ${ }^{137} \mathrm{Cs}$ (see Supplementary information, Table S.1).

Compared the two measurement methods, for water samples with low salt content such as drinking water, groundwater, and geothermal water, the thick source method generally needs to heat and evaporate 1-2 L of water to obtain no less than $0.2 \mathrm{~g}$ of residue for measurement (the diameter of the planchet is $5 \mathrm{~cm}$ ). At the same detection limit level, the LSC method only needs to heat and concentrate about $200 \mathrm{ml}$ of water, and furthermore can avoid the troublesome sample laying process. Therefore, the pretreatment process of the LSC method is more rapid and efficient. For water samples with high salt content, such as seawater, the minimum detectable concentration 
of the LSC method is 3-4 times lower than that of the thick source method because of its high detection efficiency and solid capacity. For radioactive wastewater, the LSC method can be used for direct sampling and measurement, and the pretreatment process is simple, which can effectively avoid laboratory contamination and cross-contamination of samples.

At present, there are few reports on measuring the gross $\alpha$ and gross $\beta$ of real seawater and wastewater by the LSC method ${ }^{20,27}$. However, our experimental results show that by controlling the acidity of the sample and the total amount of dissolved solids, the quenching level of the sample and the homogeneous state of the sample mixed with the scintillation liquid can be effectively controlled to ensure the reliability of LSC measurement.

\section{Conclusions}

A method for simultaneous determination of gross alpha and gross beta activity concentrations in water by LSC was established. This method is suitable for measuring colorless environmental water samples (such as drinking water, groundwater, surface water, and geothermal water), seawater, and radioactive wastewater. The chemical quenching caused by dissolved salts in water is mainly considered in LSC measurement. A simulated salt solution is used as the chemical quenching agent to calibrate the LSC measurement method, which is validated by standard spiked samples. The measurement results of real samples show that the LSC measurement results are in good agreement with the measurement results of the thick source method. In addition, the LSC method has a simpler pretreatment process and a lower detection limit.

\section{References}

1. National Standards of the People's Republic of China. Standards for Drinking Water Quality: GB5749-2006. Ministry of Health, Beijing (2006).

2. World Health Organization. Guidelines for Drinking-Water Quality. Fourth edition, World Health Organization, Geneva (2017).

3. National Standards of the People's Republic of China. Integrated wastewater discharge standard: GB 8978-1996.Ministry of Ecology and Environment, Beijing (1996).

4. ISO 9696. Water quality - Gross alpha activity - Test method using thick source. International 
Standard 9696. International Organization for Standardization, Geneva, Switzerland (2017).

5. ISO 9697. Water quality - Gross beta activity - Test method using thick source. International Standard 9697. International Organization for Standardization, Geneva, Switzerland (2018).

6. ISO 11704. Water quality - Gross alpha and gross beta activity - Test method using liquid scintillation counting. International Standard 11704. International Organization for Standardization, Geneva, Switzerland (2018).

7. ASTM International D7283-17. Standard test method for alpha and beta activity in water by liquid scintillation counting. ASTM International, 100 Barr Harbor Drive, PO Box C700, West Conshohocken, PA 19428-2959. The United States (2017).

8. Palomo, M. et al. Evaluation of different parameters affecting the liquid scintillation spectrometry measurement of gross alpha and beta index in water samples. Applied Radiation and Isotopes 69, 1274-1281 (2011).

9. Todorović, N., Nikolov, J., Tenjović, B., Bikit, I., Veskovic, M. Establishment of a method for measurement of gross alpha/beta activities in water from Vojvodina region. Radiation Measurements 47, 1053-1059 (2012).

10. Ruberu, S. R., Liu, Y. G., Kusum Perera S. An improved liquid scintillation counting method for the determination of gross alpha activity in groundwater wells. Health Physics 95, $397-406$ (2008).

11. Bhade, S. P. D. et al. Standardization of calibration procedures for quantification of gross alpha and gross beta activities using liquid scintillation counter. Journal of Radioanalytical and Nuclear Chemistry 284, 367-375 (2010).

12. Zapata-García, D., Llauradó, M., Rauret, G. The implications of particle energy and acidic media on gross alpha and gross beta determination using liquid scintillation. Applied Radiation and Isotopes 70, 705-711 (2012).

13. Kleinschmidt, R. I. Gross alpha and beta activity analysis in water - a routine laboratory method using liquid scintillation analysis. Applied Radiation and Isotopes 61, 333-338 (2004).

14. Wong, C. T., Soliman, V. M., Perera, S. K. Gross alpha/beta analyses in water by liquid scintillation counting. Journal of Radioanalytical and Nuclear Chemistry 264, 357-363 (2005). 
15. Dávila Rangel, J. I. et al. Radioactivity in bottled waters sold in Mexico. Applied Radiation and Isotopes 56, 931-936 (2002).

16. Stojković, I., Tenjović, B., Nikolov, J., Todorović, N. Possibilities and limitations of color quench correction methods for gross alpha/beta measurements. Applied Radiation and Isotopes 122, 164-173 (2017).

17. Stojković, I., Tenjović B., Nikolov, J., Todorović, N. Radionuclide, scintillation cocktail and chemical/color quench influence on discriminator setting in gross alpha/beta measurements by LSC. Journal of Environmental Radioactivity 144, 41-46 (2015).

18. Villa, M., Manjón, G., García-León, M. Study of colour quenching effects in the calibration of liquid scintillation counters: the case of ${ }^{210} \mathrm{~Pb}$. Nuclear Instruments and Methods in Physics Research A 496, 413-424 (2003).

19. Rusconi, R. et al. The evaluation of uncertainty in low-level LSC measurements of water samples. Applied Radiation and Isotopes 64, 1124-1129 (2006).

20. Zapata-García, D., Llauradó, M., Rauret, G. Establishment of a method for the rapid measurement of gross alpha and gross beta activities in sea water. Applied Radiation and Isotopes 67, 978-981 (2009).

21. Park, Y. Y., Lee, J. Y., Kim, J. H., Song, S. H. National scale evaluation of groundwater chemistry in Korea coastal aquifers: evidences of seawater intrusion. Environmental Earth Sciences 66, 707-718 (2012).

22. Stewart Fielder, D., Bardsley, W. J., Allan, G. L. Survival and growth of Australian snapper, Pagrus auratus, in saline groundwater from inland New South Wales, Australia. Aquaculture 201, 73-90 (2001).

23. ISO/IEC Guide 98-3: 2008, Uncertainty of measurement - Part 3: Guide to the expression of uncertainty in measurement (GUM: 1995).

24. Forte, M., Rusconi, R., Cazzaniga, M. T., Sgorbati, G. The measurement of radioactivity in Italian drinking waters. Microchemical Journal 85, 98-102 (2007).

25. Rusconi, R. et al. Assessment of drinking water radioactivity content by liquid scintillation counting: set up of high sensitivity and emergency procedures. Analytical and Bioanalytical Chemistry 379, 247-253 (2004).

26. Salonen, L. Alpha/beta liquid scintillation spectrometry in surveying Finnish groundwater 
samples. Radiochemistry 48, 606-612 (2006).

27. Feng, X. G., He, Q. G., Wang, J. C., Chen, J. Simultaneous determination of ${ }^{152}$ Eu and ${ }^{241}$ Am in liquid solution by liquid scintillation counting. Journal of Radioanalytical and Nuclear Chemistry 295, 1495-1503 (2013).

\section{Acknowledgements}

The authors would like to acknowledge the financial supports of the National Key R\&D Program of China (Grant Number 2018YFC1602500).

\section{Author contributions statement}

Xiaoyun Li and Shaolin Wang conceived the study and wrote the manuscript. Xiaoyun Li, Hailin Lou, and Jingshun Pan designed the experiments and analyzed the data. Qian Dong, Yifan Zheng, and Xiaoyun Li collected the samples and performed the experiments. Ling Chen explained the data and revised the manuscript.

\section{Competing interests}

The authors declare no competing interests.

\section{Additional information}

Supplementary Information, Figure S.1, Table S.1 


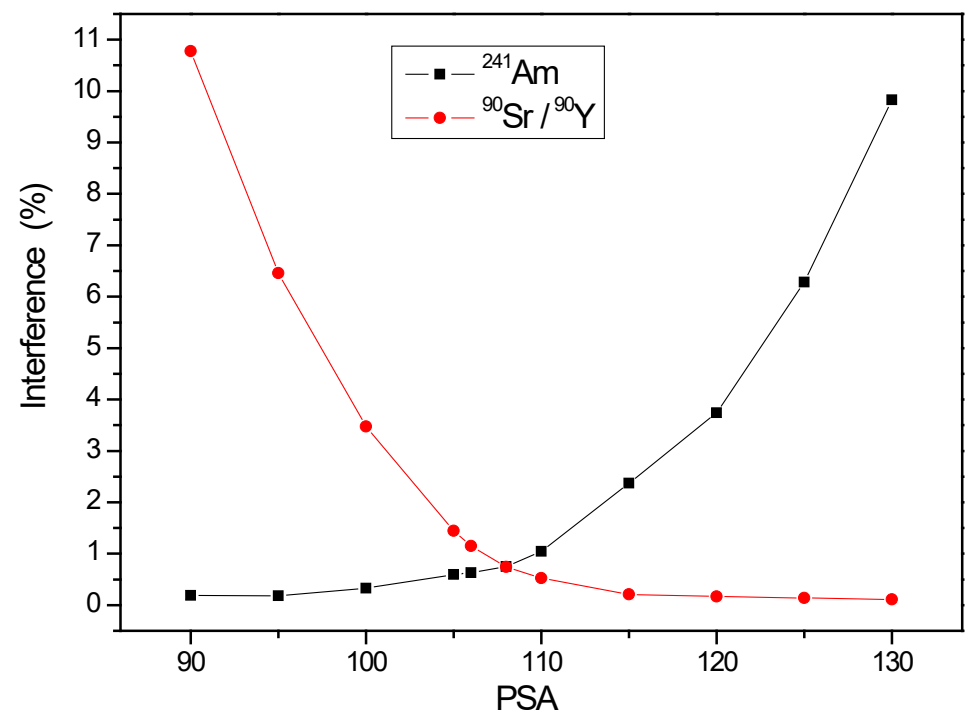

Figure 1. Calibration curves of alpha and beta interferences under different PSA settings
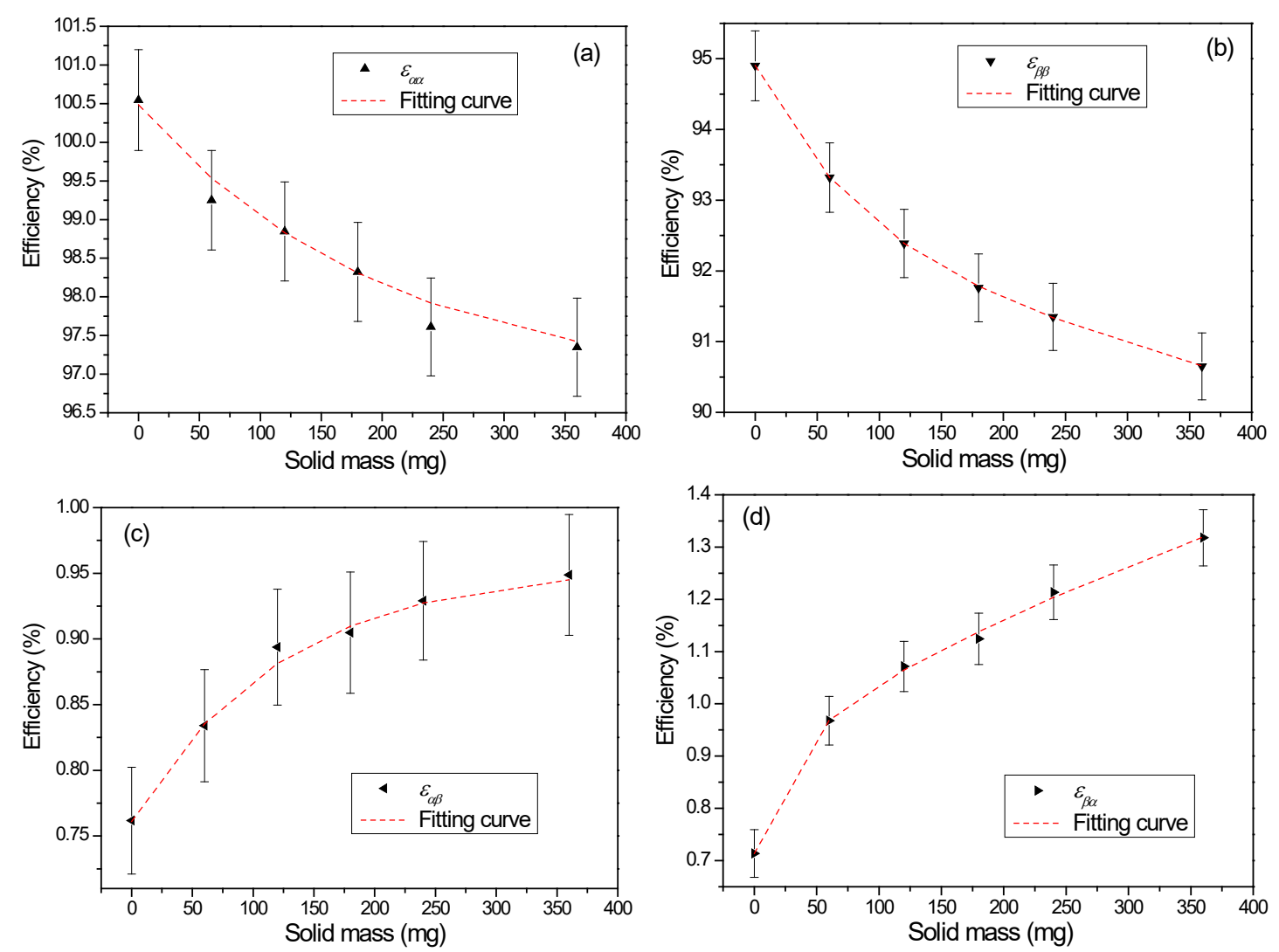

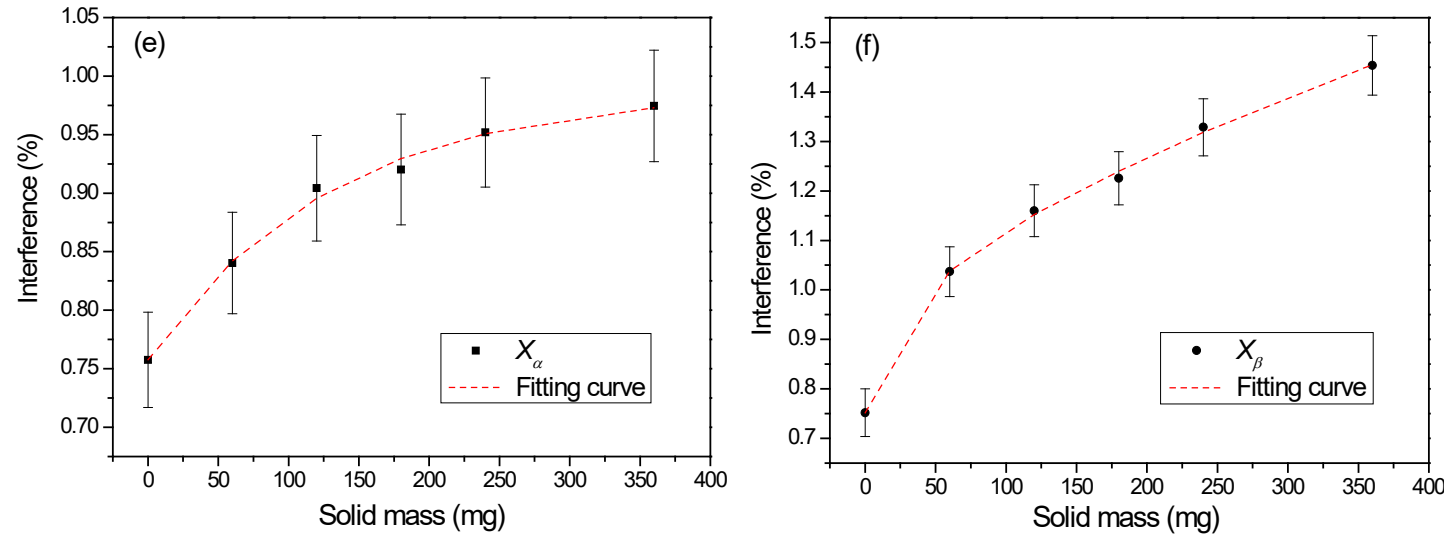

Figure 2. Calibration curves of $\varepsilon_{a a}(\mathrm{a}), \varepsilon_{\beta \beta}(\mathrm{b}), \varepsilon_{\alpha \beta}(\mathrm{c}), \varepsilon_{\beta \alpha}(\mathrm{d}), X_{\alpha}(\mathrm{e})$ and $X_{\beta}(\mathrm{f}) v s$. solid mass under the condition of PSA $=108$

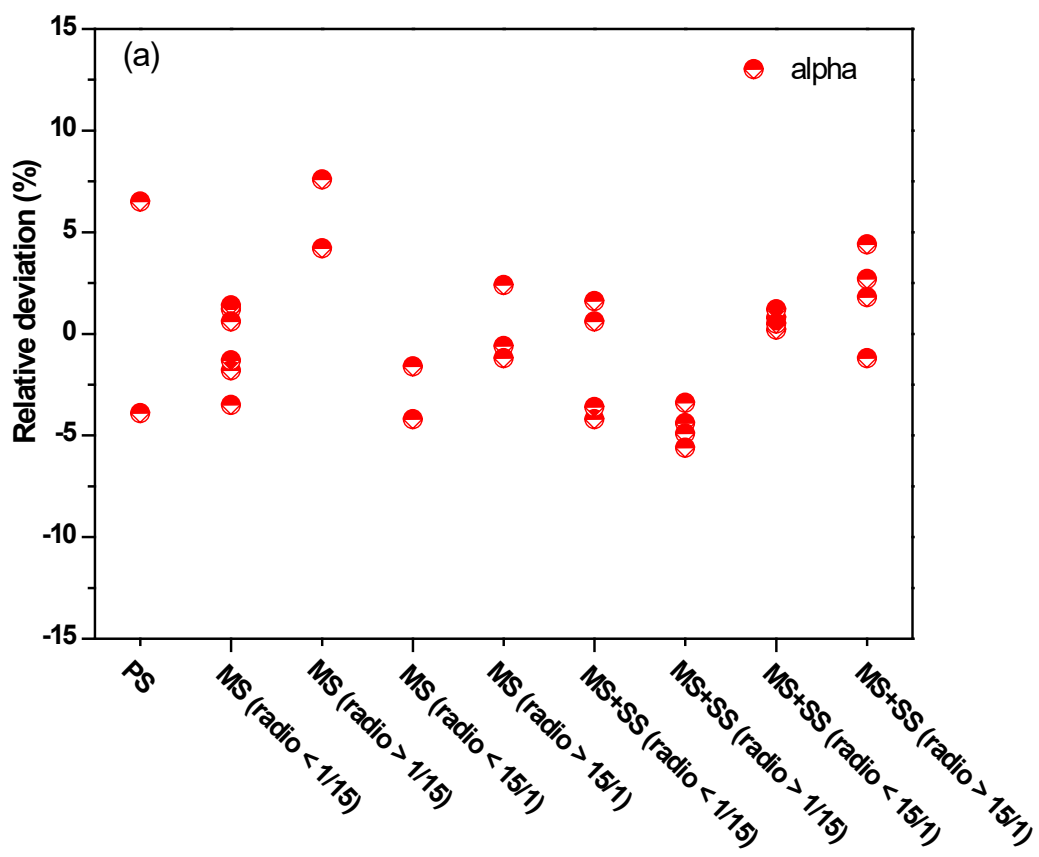




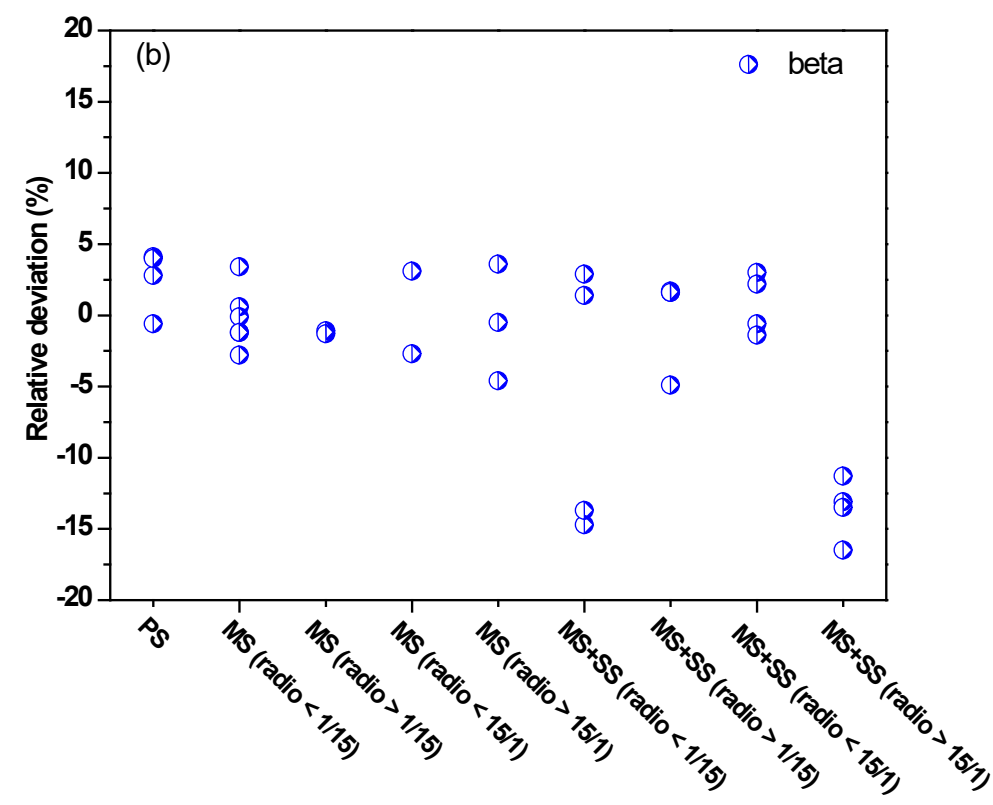

Figure S.1 The comparison of the activity relative deviations of alpha (a) and beta (b) for pure spiked samples (PS), mixed spiked samples (MS), and mixed spiked samples containing soluble salts (MS+SS). 


\begin{tabular}{|c|c|}
\hline Salt & Concentration $\left(\mathrm{g} \mathrm{L}^{-1}\right)$ \\
\hline $\mathrm{NaCl}$ & 75.5 \\
\hline $\mathrm{MgCl}_{2}$ & 30.5 \\
\hline $\mathrm{CaCl}_{2}$ & 3.3 \\
\hline $\mathrm{Na}_{2} \mathrm{SO}_{4}$ & 10.2 \\
\hline $\mathrm{NaHCO}_{3}$ & 0.5 \\
\hline Total & 120.0 \\
\hline
\end{tabular}

Table 1. Mass concentration of different salts in simulated saline water

\begin{tabular}{|c|c|}
\hline Parameters & Value $\pm u^{*}$ \\
\hline$\varepsilon_{\alpha \alpha}(\%)$ & $100.55 \pm 0.65$ \\
\hline$\varepsilon_{\alpha \beta}(\%)$ & $0.76 \pm 0.04$ \\
\hline$\varepsilon_{\beta \beta}(\%)$ & $94.90 \pm 0.49$ \\
\hline$\varepsilon_{\beta \alpha}(\%)$ & $0.71 \pm 0.05$ \\
\hline$R_{\alpha b}\left(\mathrm{~min}^{-1}\right)$ & $0.377 \pm 0.019$ \\
\hline$R_{\beta b}\left(\mathrm{~min}^{-1}\right)$ & $3.146 \pm 0.056$ \\
\hline$X_{\alpha}(\%)$ & $0.758 \pm 0.041$ \\
\hline$X_{\beta}(\%)$ & $0.752 \pm 0.048$ \\
\hline $\mathrm{SQP}(\mathrm{E})$ & $803.8 \pm 5.3$ \\
\hline
\end{tabular}

Table 2. Optimal counting parameters obtained for alpha and beta standard aliquots used in the calibration. ${ }^{*}$ The standard uncertainties correspond to $\mathrm{k}=1$. 


\begin{tabular}{|c|c|}
\hline Fitting curves & $R^{2}$ \\
\hline$\varepsilon_{a a}=96.814+3.6717 \exp \left(-0.005 m_{r}\right)$ & 0.971 \\
\hline$\varepsilon_{\beta \beta}=2.6155 \exp \left(-m_{r} / 86.9253\right)+62068.849 \exp \left(-m_{r} / 1.3341 \times 10^{7}\right)-61976.56$ & 0.998 \\
\hline$\varepsilon_{\alpha \beta}=0.956-0.195 \exp \left(-0.008 m_{r}\right)$ & 0.988 \\
\hline$\varepsilon_{\beta \alpha}=-0.1908 \exp \left(-m_{r} / 26.9048\right)-1.0292 \exp \left(-m_{r} / 697.1461\right)+1.9335$ & 0.993 \\
\hline$X_{\alpha}=0.9877-0.23 \exp \left(-0.00763 m_{r}\right)$ & 0.991 \\
\hline$X_{\beta}=-1.2121 \exp \left(-m_{r} / 687.216\right)-0.2093 \exp \left(-m_{r} / 27.9307\right)+2.1732$ & 0.994 \\
\hline
\end{tabular}

Table 3. Fitting curves of $\varepsilon_{a a}, \varepsilon_{\beta \beta}, \varepsilon_{\alpha \beta}, \varepsilon_{\beta \alpha}, X_{\alpha}$ and $X_{\beta} v s$. solid mass $\left(m_{r}, \mathrm{mg}\right)$ 


\begin{tabular}{|c|c|c|c|c|c|c|c|}
\hline Sample No. & Solid mass (mg) & $\begin{array}{l}\text { Theoretical alpha activity } \\
\qquad(\mathrm{Bq})^{\mathrm{a}}\end{array}$ & $\begin{array}{l}\text { Measured alpha activity } \\
\qquad(\mathrm{Bq})^{\mathrm{b}}\end{array}$ & $\begin{array}{l}\text { Alpha activity } \\
\text { deviation (\%) }\end{array}$ & $\begin{array}{l}\text { Theoretical beta } \\
\text { activity }(\mathrm{Bq})^{\mathrm{a}}\end{array}$ & $\begin{array}{c}\text { Measured beta activity } \\
\qquad(\mathrm{Bq})^{\mathrm{b}}\end{array}$ & $\begin{array}{l}\text { Beta activity } \\
\text { deviation (\%) }\end{array}$ \\
\hline $\mathrm{M}\left({ }^{241} \mathrm{Am}\right)$ & 0 & $2.05 \pm 0.01$ & $1.97 \pm 0.02$ & -3.9 & - & $\leq \mathrm{MDA}=7.62 \mathrm{E}-03^{\mathrm{c}}$ & - \\
\hline $\mathrm{M}\left({ }^{90} \mathrm{Sr}\right)$ & 0 & - & $\leq \mathrm{MDA}=4.41 \mathrm{E}-03^{\mathrm{c}}$ & - & $3.12 \pm 0.01$ & $3.10 \pm 0.08$ & -0.6 \\
\hline $\mathrm{M}\left({ }^{40} \mathrm{~K}\right)$ & 139 & - & $\leq \mathrm{MDA}=4.60 \mathrm{E}-03^{\mathrm{c}}$ & - & $2.11 \pm 0.05$ & $2.17 \pm 0.06$ & 2.8 \\
\hline $\mathrm{L}\left({ }^{241} \mathrm{Am}\right)$ & 0 & $(2.08 \pm 0.01)$ E- 01 & $(2.22 \pm 0.05) \mathrm{E}-01$ & 6.5 & _ & $\leq \mathrm{MDA}=6.99 \mathrm{E}-03^{\mathrm{c}}$ & \\
\hline $\mathrm{L}\left({ }^{90} \mathrm{Sr}\right)$ & 0 & - & $\leq \mathrm{MDA}=2.66 \mathrm{E}-03^{\mathrm{c}}$ & & $(3.22 \pm 0.01) \mathrm{E}-01$ & $(3.35 \pm 0.76)$ E- 01 & 4.1 \\
\hline $\mathrm{L}\left({ }^{40} \mathrm{~K}\right)$ & 14 & - & $\leq \mathrm{MDA}=2.58 \mathrm{E}-03^{\mathrm{c}}$ & - & $(2.03 \pm 0.05)$ E- 01 & $(2.11 \pm 0.67)$ E- 01 & 4.0 \\
\hline
\end{tabular}

Table 4. Validation results of pure spiked samples of ${ }^{40} \mathrm{~K},{ }^{241} \mathrm{Am}$, and ${ }^{90} \mathrm{Sr} r{ }^{90} \mathrm{Y}$ standard solution. ${ }^{2}$ Data obtained by multiplying the activity of the standard solution and the mass added. The combined standard uncertainty correspond to $\mathrm{k}=1 .{ }^{\mathrm{b}}$ The combined standard uncertainty correspond to $\mathrm{k}=1 .{ }^{\mathrm{c}} \mathrm{MDA}=$ minimum detectable activity. 


\begin{tabular}{|c|c|c|c|c|c|c|c|}
\hline Sample No. & $\begin{array}{l}\alpha / \beta \text { activity } \\
\text { ratio }\end{array}$ & $\begin{array}{l}\text { Theoretical alpha } \\
\text { activity }(\mathrm{Bq})^{\mathrm{a}}\end{array}$ & $\begin{array}{l}\text { Measured alpha } \\
\text { activity }(\mathrm{Bq})^{\mathrm{b}}\end{array}$ & $\begin{array}{l}\text { Alpha activity } \\
\text { deviation (\%) }\end{array}$ & $\begin{array}{l}\text { Theoretical beta activity } \\
\qquad(\mathrm{Bq})^{\mathrm{a}}\end{array}$ & $\begin{array}{l}\text { Measured beta activity } \\
\qquad(\mathrm{Bq})^{\mathrm{b}}\end{array}$ & $\begin{array}{c}\text { Beta activity deviation } \\
(\%)\end{array}$ \\
\hline $\mathrm{L}_{\alpha} \mathrm{L}_{\beta}$ & $1: 1.5$ & $(2.30 \pm 0.01) \mathrm{E}-01$ & $(2.26 \pm 0.05) \mathrm{E}-01$ & -1.8 & $(3.53 \pm 0.01) \mathrm{E}-01$ & $(3.55 \pm 0.06)$ E-01 & 0.6 \\
\hline $\mathrm{L}_{\alpha} \mathrm{L}_{\beta}$ & 1: 1.9 & $(6.36 \pm 0.05) \mathrm{E}-02$ & $(6.44 \pm 0.28) \mathrm{E}-02$ & 1.2 & $(1.22 \pm 0.01) \mathrm{E}-01$ & $(1.27 \pm 0.04) \mathrm{E}-01$ & 3.4 \\
\hline $\mathrm{H}_{\alpha} \mathrm{H}_{\beta}$ & $1: 1.5$ & $8.26 \pm 0.03$ & $8.15 \pm 0.04$ & -1.3 & $(1.25 \pm 0.01) \mathrm{E}+01$ & $(1.24 \pm 0.02) \mathrm{E}+01$ & -1.2 \\
\hline $\mathrm{L}_{\alpha} \mathrm{M}_{\beta}$ & $1: 12.8$ & $(2.45 \pm 0.01) \mathrm{E}-01$ & $(2.49 \pm 0.05) \mathrm{E}-01$ & 1.4 & $3.13 \pm 0.01$ & $3.12 \pm 0.05$ & -0.1 \\
\hline $\mathrm{L}_{\alpha} \mathrm{H}_{\beta}$ & $1: 50.2$ & $(2.51 \pm 0.01) \mathrm{E}-01$ & $(2.62 \pm 0.06) \mathrm{E}-01$ & 4.2 & $(1.26 \pm 0.01) \mathrm{E}+01$ & $(1.24 \pm 0.02) \mathrm{E}+01$ & -1.0 \\
\hline $\mathrm{L}_{\alpha} \mathrm{H}_{\beta}$ & $1: 84.5$ & $(1.48 \pm 0.01) \mathrm{E}-01$ & $(1.59 \pm 0.05) \mathrm{E}-01$ & 7.6 & $(1.25 \pm 0.01) \mathrm{E}+01$ & $(1.23 \pm 0.02) \mathrm{E}+01$ & -1.0 \\
\hline $\mathrm{M}_{\alpha} \mathrm{H}_{\beta}$ & 1: 5.9 & $2.12 \pm 0.01$ & $2.13 \pm 0.02$ & 0.6 & $(1.25 \pm 0.01) \mathrm{E}+01$ & $(1.23 \pm 0.02) \mathrm{E}+01$ & -1.2 \\
\hline $\mathrm{M}_{\alpha} \mathrm{M}_{\beta}$ & $1: 1.5$ & $2.10 \pm 0.01$ & $2.02 \pm 0.02$ & -3.5 & $3.15 \pm 0.01$ & $3.06 \pm 0.02$ & -2.8 \\
\hline $\mathrm{M}_{\alpha} \mathrm{L}_{\beta}$ & $6.0: 1$ & $2.11 \pm 0.01$ & $2.02 \pm 0.02$ & -4.2 & $(3.49 \pm 0.01) \mathrm{E}-01$ & $(3.60 \pm 0.03) \mathrm{E}-01$ & 3.1 \\
\hline $\mathrm{M}_{\alpha} \mathrm{L}_{\beta}$ & 24.1: 1 & $4.10 \pm 0.02$ & $4.08 \pm 0.03$ & -0.6 & $(1.70 \pm 0.01) \mathrm{E}-01$ & $(1.76 \pm 0.02) \mathrm{E}-01$ & 3.6 \\
\hline $\mathrm{H}_{\alpha} \mathrm{L}_{\beta}$ & 22.6: 1 & $8.30 \pm 0.03$ & $8.21 \pm 0.04$ & -1.2 & $(3.67 \pm 0.01) \mathrm{E}-01$ & $(3.65 \pm 0.03) \mathrm{E}-01$ & -0.5 \\
\hline $\mathrm{H}_{\alpha} \mathrm{L}_{\beta}$ & 66.1: 1 & $9.92 \pm 0.04$ & $(1.02 \pm 0.02) \mathrm{E}+01$ & 2.4 & $(1.50 \pm 0.01) \mathrm{E}-01$ & $(1.43 \pm 0.02) \mathrm{E}-01$ & -4.6 \\
\hline $\mathrm{H}_{\alpha} \mathrm{M}_{\beta}$ & 2.6: 1 & $8.21 \pm 0.03$ & $8.08 \pm 0.04$ & -1.6 & $3.14 \pm 0.01$ & $3.06 \pm 0.02$ & -2.7 \\
\hline
\end{tabular}

Table 5. Validation results of mixed spiked samples of ${ }^{241} \mathrm{Am}$, and ${ }^{90} \mathrm{Sr} /{ }^{90} \mathrm{Y}$ standard solution (solid mass $=0$ ). ${ }^{\text {aD }}$ Data obtained by multiplying the activity of the standard solution and the mass added. The combined standard uncertainty correspond to $\mathrm{k}=1{ }^{\mathrm{b}}$ The combined standard uncertainty correspond to $\mathrm{k}=1$. 


\begin{tabular}{|c|c|c|c|c|c|c|c|c|}
\hline Sample No. & $\begin{array}{l}\text { Solid mass } \\
\text { (mg) }\end{array}$ & $\alpha / \beta$ activity ratio & $\begin{array}{c}\text { Theoretical alpha } \\
\text { activity }(\mathrm{Bq})^{\mathrm{a}}\end{array}$ & $\begin{array}{l}\text { Measured alpha } \\
\text { activity }(\mathrm{Bq})^{\mathrm{b}}\end{array}$ & $\begin{array}{l}\text { Alpha activity } \\
\text { deviation (\%) }\end{array}$ & $\begin{array}{l}\text { Theoretical beta } \\
\text { activity }(\mathrm{Bq})^{\mathrm{a}}\end{array}$ & $\begin{array}{l}\text { Measured beta } \\
\text { activity }(\mathrm{Bq})^{\mathrm{b}}\end{array}$ & $\begin{array}{l}\text { Beta activity } \\
\text { deviation (\%) }\end{array}$ \\
\hline $\mathrm{L}_{\alpha} \mathrm{L}_{\beta}$ & 180 & $1: 1.6$ & $(1.09 \pm 0.01) \mathrm{E}-01$ & $(1.04 \pm 0.04)$ E-01 & -4.2 & $(1.71 \pm 0.01) \mathrm{E}-01$ & $(1.46 \pm 0.04) \mathrm{E}-01$ & -14.7 \\
\hline $\mathrm{L}_{\alpha} \mathrm{L}_{\beta}$ & 360 & 1: 1.9 & $(9.23 \pm 0.05) \mathrm{E}-02$ & $(8.90 \pm 0.33) \mathrm{E}-02$ & -3.6 & $(1.77 \pm 0.01) \mathrm{E}-01$ & $(1.53 \pm 0.04) \mathrm{E}-01$ & -13.7 \\
\hline $\mathrm{H}_{\alpha} \mathrm{H}_{\beta}$ & 180 & $1: 1.5$ & $8.23 \pm 0.03$ & $8.28 \pm 0.04$ & 0.6 & $(1.25 \pm 0.01) \mathrm{E}+01$ & $(1.28 \pm 0.02) \mathrm{E}+01$ & 1.4 \\
\hline $\mathrm{H}_{\alpha} \mathrm{H}_{\beta}$ & 360 & $1: 1.5$ & $8.21 \pm 0.03$ & $8.34 \pm 0.04$ & 1.6 & $(1.26 \pm 0.01) \mathrm{E}+01$ & $(1.29 \pm 0.02) \mathrm{E}+01$ & 2.9 \\
\hline $\mathrm{L}_{\alpha} \mathrm{M}_{\beta}$ & 180 & $1: 16.7$ & $(2.06 \pm 0.01) \mathrm{E}-01$ & $(1.99 \pm 0.05) \mathrm{E}-01$ & -3.4 & $3.43 \pm 0.01$ & $3.48 \pm 0.06$ & 1.6 \\
\hline $\mathrm{L}_{\alpha} \mathrm{M}_{\beta}$ & 360 & $1: 16.0$ & $(2.26 \pm 0.01) \mathrm{E}-01$ & $(2.16 \pm 0.05) \mathrm{E}-01$ & -4.4 & $3.61 \pm 0.01$ & $3.43 \pm 0.05$ & -4.9 \\
\hline $\mathrm{L}_{\alpha} \mathrm{H}_{\beta}$ & 180 & $1: 87.5$ & $(1.44 \pm 0.01) \mathrm{E}-01$ & $(1.37 \pm 0.05) \mathrm{E}-01$ & -4.9 & $(1.26 \pm 0.01) \mathrm{E}+01$ & $(1.28 \pm 0.02) \mathrm{E}+01$ & 1.7 \\
\hline $\mathrm{L}_{\alpha} \mathrm{H}_{\beta}$ & 360 & 1: 101.6 & $(1.24 \pm 0.01) \mathrm{E}-01$ & $(1.17 \pm 0.06) \mathrm{E}-01$ & -5.6 & $(1.26 \pm 0.01) \mathrm{E}+01$ & $(1.28 \pm 0.02) \mathrm{E}+01$ & 1.6 \\
\hline $\mathrm{M}_{\alpha} \mathrm{M}_{\beta}$ & 180 & 1.3: 1 & $4.11 \pm 0.02$ & $4.14 \pm 0.03$ & 0.8 & $3.21 \pm 0.01$ & $3.19 \pm 0.02$ & -0.6 \\
\hline $\mathrm{M}_{\alpha} \mathrm{M}_{\beta}$ & 360 & 1.3: 1 & $4.13 \pm 0.02$ & $4.17 \pm 0.03$ & 1.2 & $3.17 \pm 0.01$ & $3.26 \pm 0.02$ & 3.0 \\
\hline $\mathrm{M}_{\alpha} \mathrm{L}_{\beta}$ & 180 & 24.7: 1 & $4.10 \pm 0.02$ & $4.17 \pm 0.03$ & 1.8 & $(1.66 \pm 0.01) \mathrm{E}-01$ & $(1.44 \pm 0.02) \mathrm{E}-01$ & -13.1 \\
\hline $\mathrm{M}_{\alpha} \mathrm{L}_{\beta}$ & 360 & $23.0: 1$ & $4.10 \pm 0.02$ & $4.21 \pm 0.03$ & 2.7 & $(1.78 \pm 0.01) \mathrm{E}-01$ & $(1.58 \pm 0.02) \mathrm{E}-01$ & -11.3 \\
\hline $\mathrm{H}_{\alpha} \mathrm{L}_{\beta}$ & 180 & 67.3: 1 & $(1.05 \pm 0.01) \mathrm{E}+01$ & $(1.04 \pm 0.02) \mathrm{E}+01$ & -1.2 & $(1.56 \pm 0.01) \mathrm{E}-01$ & $(1.30 \pm 0.03) \mathrm{E}-01$ & -16.5 \\
\hline $\mathrm{H}_{\alpha} \mathrm{L}_{\beta}$ & 360 & 64.3: 1 & $(1.01 \pm 0.01) \mathrm{E}+01$ & $(1.05 \pm 0.02) \mathrm{E}+01$ & 4.4 & $(1.57 \pm 0.01) \mathrm{E}-01$ & $(1.36 \pm 0.03) \mathrm{E}-01$ & -13.5 \\
\hline $\mathrm{H}_{\alpha} \mathrm{M}_{\beta}$ & 180 & 2.6: 1 & $8.21 \pm 0.03$ & $8.22 \pm 0.04$ & 0.2 & $3.12 \pm 0.01$ & $3.07 \pm 0.02$ & -1.4 \\
\hline $\mathrm{H}_{\alpha} \mathrm{M}_{\beta}$ & 360 & 2.8: 1 & $8.23 \pm 0.03$ & $8.28 \pm 0.04$ & 0.5 & $2.99 \pm 0.01$ & $3.06 \pm 0.02$ & 2.2 \\
\hline
\end{tabular}

Table 6. Validation results of mixed spiked samples of ${ }^{241} \mathrm{Am}$, and ${ }^{90} \mathrm{Sr} /{ }^{90} \mathrm{Y}$ standard solution in simulated saline water. ${ }^{\mathrm{a}}$ Data obtained by multiplying the activity of the standard solution and the mass added. The combined standard uncertainty correspond to $\mathrm{k}=1 .{ }^{\mathrm{b}}$ The combined standard uncertainty correspond to $\mathrm{k}=1$. 


\begin{tabular}{|c|c|c|c|c|c|c|c|c|}
\hline \multirow[t]{2}{*}{ Sample No. } & \multirow[t]{2}{*}{ Total solid content $\left(\mathrm{mg} \mathrm{L}^{-1}\right)$} & \multirow[t]{2}{*}{ SQP(E) } & \multicolumn{3}{|c|}{ Gross alpha activity concentration } & \multicolumn{3}{|c|}{ Gross beta activity concentration } \\
\hline & & & Reference value $(\mathrm{Bq} / \mathrm{L})^{*}$ & Measured value $(\mathrm{Bq} / \mathrm{L})^{*}$ & Z-Score & Reference value $(\mathrm{Bq} / \mathrm{L})^{*}$ & Measured value $(\mathrm{Bq} / \mathrm{L})^{*}$ & Z-Score \\
\hline IS-2019 & $6.89 \mathrm{E}+02$ & 796.3 & $(8.80 \pm 0.30) \mathrm{E}-01$ & $1.04 \pm 0.04$ & 1.0 & $(6.20 \pm 0.20) \mathrm{E}-01$ & $(6.92 \pm 0.33) \mathrm{E}-01$ & 0.9 \\
\hline IS-2020 & $1.42 \mathrm{E}+03$ & 795.4 & $(7.80 \pm 0.40) \mathrm{E}-01$ & $(6.51 \pm 0.55) \mathrm{E}-01$ & -1.2 & $(3.50 \pm 0.20) \mathrm{E}-01$ & $(3.10 \pm 0.24) \mathrm{E}-01$ & -0.8 \\
\hline
\end{tabular}

Table 7. The results of gross alpha and gross beta activity concentrations for water samples from proficiency tests. ${ }^{*}$ The combined standard uncertainty correspond to $\mathrm{k}=1$. 


\begin{tabular}{|c|c|c|c|c|c|c|c|c|c|c|}
\hline \multirow{2}{*}{$\begin{array}{l}\text { Sample } \\
\text { No. }\end{array}$} & \multirow{2}{*}{$\begin{array}{l}\text { Total solid } \\
\text { content } \\
\left(\mathrm{mg} \mathrm{L}^{-1}\right)\end{array}$} & \multicolumn{4}{|c|}{ LSC method ${ }^{\mathrm{a}}$} & \multicolumn{3}{|c|}{ Thick source method ${ }^{\mathrm{a}, \mathrm{b}}$} & \multicolumn{2}{|c|}{ Deviation $(\%)^{\mathrm{c}}$} \\
\hline & & $\begin{array}{l}\text { Mass of the } \\
\text { test sample }(\mathrm{g})\end{array}$ & SQP(E) & $\begin{array}{l}\text { Gross alpha activity } \\
\text { concentration }\left(\mathrm{Bq} \mathrm{L}^{-1}\right)\end{array}$ & $\begin{array}{c}\text { Gross beta activity } \\
\text { concentration }\left(\mathrm{Bq} \mathrm{L}^{-1}\right)\end{array}$ & $\begin{array}{l}\text { Mass of the } \\
\text { test sample (g) }\end{array}$ & $\begin{array}{l}\text { Gross alpha activity } \\
\text { concentration }\left(\mathrm{Bq} \mathrm{L}^{-1}\right)\end{array}$ & $\begin{array}{c}\text { Gross beta activity } \\
\text { concentration }\left(\mathrm{Bq} \mathrm{L}^{-1}\right)\end{array}$ & $\begin{array}{l}\text { Gross } \\
\text { alpha }\end{array}$ & $\begin{array}{l}\text { Gross } \\
\text { beta }\end{array}$ \\
\hline DW-1 & $3.60 \mathrm{E}+02$ & $2.02 \mathrm{E}+02$ & 797.5 & $(4.16 \pm 0.68) \mathrm{E}-02$ & $(1.21 \pm 0.12) \mathrm{E}-01$ & $2.00 \mathrm{E}+03$ & $(3.77 \pm 0.85) \mathrm{E}-02$ & $(1.06 \pm 0.11) \mathrm{E}-01$ & 10.3 & 14.2 \\
\hline DW-2 & $2.65 \mathrm{E}+02$ & $2.02 \mathrm{E}+02$ & 800.3 & $(2.55 \pm 0.60)$ E-02 & $(1.11 \pm 0.12) \mathrm{E}-01$ & $2.00 \mathrm{E}+03$ & $(2.32 \pm 0.68)$ E-02 & $(1.17 \pm 0.12)$ E-01 & 9.9 & -5.1 \\
\hline GW-1 & $3.40 \mathrm{E}+02$ & $2.02 \mathrm{E}+02$ & 798.5 & $\leq \mathrm{MDC}=1.22 \mathrm{E}-02$ & $(7.8 \pm 1.2)$ E-02 & $2.00 \mathrm{E}+03$ & $\leq \mathrm{MDC}=1.81 \mathrm{E}-02$ & $(8.3 \pm 1.2)$ E-02 & - & -5.43 \\
\hline GW-2 & $2.04 \mathrm{E}+02$ & $2.03 \mathrm{E}+02$ & 799.0 & $(2.45 \pm 0.60) \mathrm{E}-02$ & $(3.8 \pm 1.1) \mathrm{E}-02$ & $2.00 \mathrm{E}+03$ & $(2.18 \pm 0.52) \mathrm{E}-02$ & $(3.35 \pm 0.98) \mathrm{E}-02$ & 12.4 & 12.5 \\
\hline GT-1 & $3.03 \mathrm{E}+02$ & $2.04 \mathrm{E}+02$ & 797.3 & $(1.88 \pm 0.11) \mathrm{E}-01$ & $(5.82 \pm 0.17)$ E-01 & $2.00 \mathrm{E}+03$ & $(2.03 \pm 0.14) \mathrm{E}-01$ & $(6.15 \pm 0.23) \mathrm{E}-01$ & -7.4 & -5.4 \\
\hline GT-2 & $5.09 \mathrm{E}+02$ & $2.04 \mathrm{E}+02$ & 796.5 & $(1.84 \pm 0.56) \mathrm{E}-02$ & $(5.11 \pm 0.17) \mathrm{E}-01$ & $1.00 \mathrm{E}+03$ & $\leq \mathrm{MDC}=3.87 \mathrm{E}-02$ & $(4.76 \pm 0.15) \mathrm{E}-01$ & - & 7.4 \\
\hline SW-1 & $2.39 \mathrm{E}+04$ & 5.03 & 793.4 & $\leq \mathrm{MDC}=4.97 \mathrm{E}-01$ & $9.91 \pm 0.55$ & $5.01 \mathrm{E}+01$ & $\leq \mathrm{MDC}=1.41$ & $9.34 \pm 0.59$ & - & 6.1 \\
\hline SW-2 & $3.22 \mathrm{E}+04$ & 5.03 & 790.7 & $\leq \mathrm{MDC}=4.98 \mathrm{E}-01$ & $9.28 \pm 0.55$ & $5.00 \mathrm{E}+01$ & $\leq \mathrm{MDC}=2.15$ & $8.85 \pm 0.51$ & - & 4.9 \\
\hline WW-1 & $1.40 \mathrm{E}+04$ & 5.05 & 796.9 & $(5.43 \pm 2.21) \mathrm{E}-01$ & $(1.34 \pm 0.01) \mathrm{E}+01$ & $5.02 \mathrm{E}+01$ & $(5.72 \pm 2.90) \mathrm{E}-01$ & $(1.45 \pm 0.03) \mathrm{E}+01$ & -5.1 & -7.6 \\
\hline WW-2 & $9.81 \mathrm{E}+03$ & 5.04 & 799.3 & $2.35 \pm 0.30$ & $6.27 \pm 0.50$ & $5.01 \mathrm{E}+01$ & $2.16 \pm 0.28$ & $6.48 \pm 0.57$ & 8.8 & -3.2 \\
\hline
\end{tabular}

Table 8. The results of gross alpha and gross beta activity concentrations of different kinds of water samples determined using LSC and thick source methods. ${ }^{a}$ The combined standard uncertainty correspond to $\mathrm{k}=1$. $^{\mathrm{b}}$ The measurement time of samples and background are all 10 hours. ${ }^{\mathrm{c}}$ The deviation of the results of the LSC method relative to the results of the thick source method. 


\begin{tabular}{|c|c|c|c|}
\hline \multirow{2}{*}{ Sample No. } & \multicolumn{3}{|c|}{ Radionuclide activity concentration $(\mathrm{Bq} / \mathrm{L})^{*}$} \\
\cline { 2 - 4 } & ${ }^{40} \mathrm{~K}$ & ${ }^{137} \mathrm{Cs}$ & ${ }^{241} \mathrm{Am}$ \\
\hline $\mathrm{SW}-1$ & $9.30 \pm 0.45$ & $\leq \mathrm{MDC}=2.32 \mathrm{E}-01$ & $\leq \mathrm{MDC}=2.60 \mathrm{E}-01$ \\
\hline $\mathrm{SW}-2$ & $9.89 \pm 0.50$ & $\leq \mathrm{MDC}=2.21 \mathrm{E}-01$ & $\leq \mathrm{MDC}=2.55 \mathrm{E}-01$ \\
\hline $\mathrm{WW}-1$ & $\leq \mathrm{MDC}=4.16$ & $(1.29 \pm 0.08) \mathrm{E}+01$ & $(6.08 \pm 0.32) \mathrm{E}-01$ \\
\hline $\mathrm{WW}-2$ & $\leq \mathrm{MDC}=4.35$ & $6.15 \pm 0.38$ & $2.09 \pm 0.15$ \\
\hline
\end{tabular}

Table S.1 The results of gamma spectrometry measurements for the seawater and wastewater samples. ${ }^{*}$ The combined standard uncertainty correspond to $\mathrm{k}=1$. 


\section{Supplementary Files}

This is a list of supplementary files associated with this preprint. Click to download.

- SupplementaryInformationforScientificReports.docx 